\title{
A PROSPECTIVE STUDY ON GERIATRIC PRESCRIBING PATTERN AND MEDICATION ADHERENCE IN A TERTIARY CARE HOSPITAL
}

\author{
SEEMA ANJUM M*, CHINCHU JACOB, AKHIL BENCHAMIN, PRUDENCE A RODRIGUES
}

Department of Pharmacy Practice, PSG College of Pharmacy, Coimbatore, Tamil Nadu India. Email: seemaanjum211@gmail.com

Received: 05 June 2017, Revised and Accepted: 30 August 2017

\section{ABSTRACT}

Objectives: To identify potentially inappropriate medications (PIMs) using Beers criteria 2015 and to recommend safer alternative medication for the above. To assess the medication adherence in geriatric patients and to categorize according to their adherence.

Methods: This is prospective, interventional study. A total of 90 patients aged 65 years and above were involved in the study. Data were collected and recorded. The prescriptions were analyzed for appropriateness using updated Beers criteria 2015 and assess medication adherence using 8-item Morisky questionnaire.

Results: Majority of the patients were in the age group of 65-74 years. Males (53\%) showed predominance than females. The highest rate of (53\%) polypharmacy was found in general medicine department than other departments. Out of 147 disease conditions observed, chronic renal failure (21.1\%) was the most common condition. A total of 66 patients had comorbid conditions. Most frequently prescribed medications belonged to cardiovascular drugs (56; 14.62\%). A total of 46 patients received PIMs; majority belonged to Category 1 - amitriptyline. Commonly prescribed medication in PIMs belonged to central nervous system medications (20\%). Majority of patients were low adherent (51.11\%) in which female patients showed preponderance in low adherence.

Conclusion: Study showed prevalence of disease pattern, medication use, polypharmacy, PIMs, and medication adherence. It is important for pharmacists to stay updated and prescribers need to be educated and encouraged about Beers criteria for rational prescription for better pharmaceutical care and increased medication adherence.

Keywords: Potentially inappropriate medication, Geriatrics, Polypharmacy, Beer's criteria, Morisky 8 item scale, Medication adherence.

(C) 2017 The Authors. Published by Innovare Academic Sciences Pvt Ltd. This is an open access article under the CC BY license (http://creativecommons. org/licenses/by/4. 0/) DOI: http://dx.doi.org/10.22159/ajpcr.2017.v10i12.20460

\section{INTRODUCTION}

At present, in India the elderly population accounts for $7.4 \%$ of total population, it is projected to rise to $12.4 \%$ of the population by the year 2026. India has the third place after China and the USA in terms of elderly population [1]. It is commonly observed that geriatrics suffer from multiple comorbid conditions and is also hospitalized several times, so there is an increased occurrence of polypharmacy and drugrelated issues which needs to be addressed. In the elderly, prescription of potentially inappropriate medications (PIMs) has been found to be the common cause of morbidity and mortality. PIM is defined as "a drug in which the risk of an adverse event outweighs its clinical benefit, particularly when there is a safer or more effective alternate therapy for the same condition is available." Many studies have shown the occurrence of adverse drug reactions due to PIMs. It is therefore necessary for the health care team to look into issues of polypharmacy, eliminate barriers to medication adherence, and restrict prescribing medications to the geriatric population [2] It is important to identify the PIM use in this vulnerable group to minimize pharmacotherapy-related hazards [3]. PIM is an important triggering factor for the creation of criteria for the safe use of medicines among the elderly, namely, the Beers criteria, which was initially released in 1997 and updated in 2002, 2012, and 2015 [4]. The Beers criteria for the PIM use in older adults commonly called as Beers list, it is the guideline for health-care professionals to help improvise on the safety of prescribing medications for the older adults. It emphasizes on deprescribing medication that is unnecessary [5]. The Beers criteria provide information based on quality of evidence and strength of recommendations.

According to Beer's criteria, medications which are prescribed inappropriately are classified into one of the following categories:
Group I-Medications which are considered to be potentially inappropriate in older adults.

Group II - Medications which may exacerbate existing disease or syndrome.

Group III - Medications to be used with caution in older adults.

It is observed that $10-31 \%$ of hospital admissions (emergency department visits) by geriatrics are associated with greater use of PIMs [6].

Medications adherence usually refers to whether patients take their medications as prescribed, as well as whether they continue to take the prescribed medication. Medication nonadherence is a growing concern to clinicians, health-care systems. Because of mounting evidence that it is prevalent and associated with adverse outcomes and higher costs of care [7].

\section{METHODS}

\section{Study design}

A hospital-based prospective - interventional study, involving patients aged 65 years and above and conducted over a period of 6 months from march 2016 to august 2016 in PSG Institute of Medical Science and Research Centre, Coimbatore. The Institutional Human Ethics Committee was approved with the proposal number of 16/062.

\section{Sample selection}

Patients of either gender aged 65 years and above of Cardiology, Neurology, and General Medicine were included in the study.

\section{Population size}

As per Raosoft software, the sample size was estimated to be around 90 . The margin of error is $5 \%$ and confidence interval is $95 \%$. 


\section{Data source}

Patient history, treatment charts, laboratory reports, physician guidance, and hospital information system.

\section{Patient selection}

\section{Inclusion criteria}

Patients of either sex admitted to the respective study site during study duration.

Patients aged 65 years and above, patients with comorbid conditions, patient with previous medication history, patients who were willing to participate in the study.

\section{Exclusion criteria}

Patient who aged below 65 years, terminally ill patients requiring intensive care unit admission; and mentally unstable patients were excluded from the study.

\section{Study plan}

During the study period, 90 geriatric patients were identified based upon the inclusion and exclusion criteria. Informed consent was obtained. They were assessed for medication adherence using Morisky 8 item medication adherence questionnaire and PIMs were identified using American Geriatric Society updated Beers Criteria 2015. Patients received general health care through Physicians and Nurses and education through the pharmacists.

\section{Statistical analysis}

Based on patient demographics, major diagnosis observed in the study population, no of medications per prescription, categories of drug prescribed, categories of medications prescribed, patients with comorbid conditions were statistically analyzed evaluation of prescription using Beers criteria 2015, errors identified in prescriptions, categorization of medications according to Beers criteria, common categories of PIMs in geriatrics, safer alternatives in geriatrics, evaluation of medication adherence, sex distribution in low medication adherence.

\section{RESULTS}

In 6-month period of study, a total of 90 patients aged 65 years and above were included and analyzed. Among 90 patients, majority were in the age group of $65-74$ years (51\%), followed by age group of $75-84$ years ( $32 \%)$ and $\geq 85$ years were $7 \%$.

Among 90 patients, 48 (53\%) were male and 42 (47\%) were female.

According to the department-wise distribution, the highest numbers of patients were in general medicine (53\%), followed by neurology (25\%), and cardiology (22\%).

Most frequently identified diseases in geriatrics were chronic renal failure (CRF) (21.1\%), systemic hypertension (SHT) (18.8\%), acute renal failure (ARF) $(18.8 \%)$ congestive heart failure (CHF) $(17.7 \%)$, diabetes mellitus (DM) (17.7\%), cerebrovascular accident (CVA) (16.6\%), coronary artery disease (CAD) $(14.40 \%)$, cirrhosis $(11.11 \%)$, and gastro esophageal reflux disease (7.7\%), as shown in Fig. 1.

Of all the prescriptions evaluated, $10 \%$ were found to have 1-4 medications, $40 \%$ with 5-9 medications, $38 \%$ with $10-14$ medications, $8.9 \%$ with $15-19$ medications, and $3.33 \%$ with $\geq 20$ medications, respectively as shown in Table 1.

A total of 383 medications were prescribed under different categories for geriatric patients. Out of these, the most commonly prescribed medications were cardio vascular drugs $14.62 \%$, central nervous system (CNS) medications (14.09\%), gastrointestinal medications (12.53\%), respiratory medications (11.48\%), analgesic and anti-inflammatory medications (9.39\%), anti-diabetic medications (8.87\%). The least prescribed medications were hematological (6.00\%), anti-histaminic medications (4.49\%) and anti-epileptic medications (4.43\%) as shown in Table 2.

Out of 90 patients, 66 patients had comorbid condition, as shown in Table 3 .

Out of 90 prescriptions, $48.88 \%$ of the prescriptions were appropriate and $51.11 \%$ were inappropriate, as shown in Fig. 2.

Table 1: Number of medications per prescription $(n=90)$

\begin{tabular}{lll}
\hline $\begin{array}{l}\text { Number of } \\
\text { medications }\end{array}$ & Frequency of occurrence & Percentage \\
\hline $1-4$ & 9 & 10 \\
$5-9$ & 36 & 40 \\
$10-14$ & 34 & 37.7 \\
$15-19$ & 8 & 8.88 \\
$\geq 20$ & 3 & 3.33 \\
\hline
\end{tabular}

Table 2: Categories of medications prescribed $(n=90)$

\begin{tabular}{lll}
\hline S. No. & Categories of medications & No. of medications (\%) \\
\hline 1 & Gastrointestinal medications & $48(12.53)$ \\
2 & Respiratory medications & $44(11.48)$ \\
3 & Cardiovascular medications & $56(14.62)$ \\
4 & Medications acting on central & $54(14.09)$ \\
& nervous system & $17(4.43)$ \\
5 & Anti-epileptic medications & $34(8.87)$ \\
6 & Anti-diabetic medications & $23(6.00)$ \\
7 & Medications acting on & \\
8 & hematological system & $36(9.39)$ \\
& Analgesic and anti-inflammatory \\
9 & medications & \\
10 & Anti-histamine medications & $19(4.96)$ \\
& Medications acting on renal & $17(4.43)$ \\
11 & system & $35(9.13)$ \\
\hline
\end{tabular}

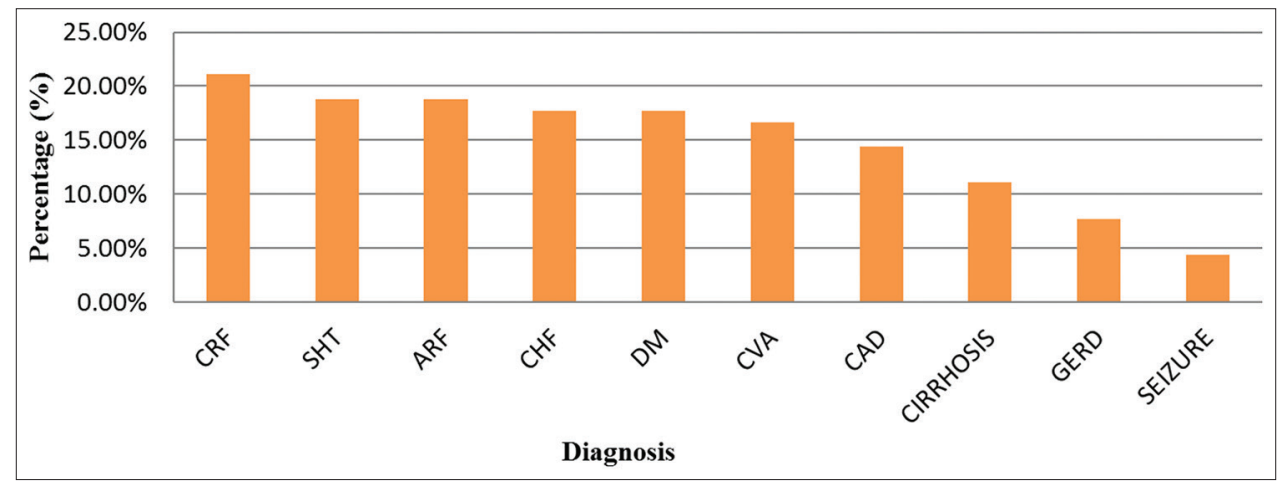

Fig. 1: Most frequently observed disease conditions among geriatrics $(n=90)$ 


\section{Errors identified in prescriptions}

As the results indicated, $51.11 \%$ of the prescriptions with inappropriate medications were identified based on Beers criteria as shown in Fig. 3.

Medication identified under Category 1 is - amitriptyline, lorazepam, spironolactone, hydroxyzine and diclofenac, nitrofurantoin, alprazolam and prazosin, clonazepam and zolpidem were identified. Under Category 2 - such as modfinil, diltiazem, theophylline, and metoclopramide. Medications under Category 3 - such as furosemide, tramadol, aspirin, carbamazepine, toresamide, paracetamol, and prednisolone + nonsteroidal anti-inflammatory drug (NSAIDs) are shown in Table 4.

Common categories of PIMs in elderly were most frequently prescribed from CNS medications (20\%), followed by cardiovascular medications (18.46\%), benzodiazepines (15.38\%), diuretics (13.84\%), opiods (9.230\%), NSAIDs (7.69\%), and anti-microbial agents (4.61\%) (Table 5).

8-item Morisky scales was used to evaluate medication adherence. Out of 90 patients, $51.11 \%$ were with low adherence, $35.55 \%$ with medium adherence, and $13.33 \%$ patients with high adherence as shown in Table 6.

In this study, out of 90 patients, 46 were low adherent patients. Female patients showed predominance in low medication adherence than male patients as in Table 7 .

\section{DISCUSSION}

The age of patients included in the study was greater than 65 years. Maximum patients were in the age group ranging from 65 to 74 years,

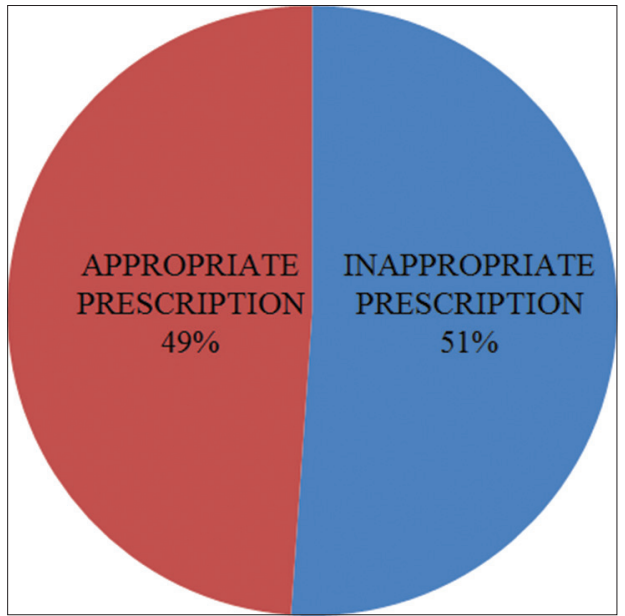

Fig. 2: Evaluation of prescription using Beers criteria 2015 (n=90) followed by patients in the age group of 75-84 years, similar age distributions were seen in a study (Prakash Goudanavar et al. Asian journal of biomedical and pharmaceutical sciences 2016).

This study showed male predominance, similar sex distribution were seen in the study done by Supriya Pradhan et al. IJMEDPH February 2016 in the state of Odisha). This was justified because in developing countries like India disorders such as cardiovascular disorder, DM were more prevalent in male than in female.

This current study shows that among the total 90 patients who were admitted, majority were in general medicine (53\%) followed by neurology department (25\%). This can be justified as most of the patients suffering from hypertension, CAD, renal failure, CHF, DM, and CVA consulted the particular departments. Among geriatric patients, the prevalence of disorders was highest in kidney disease, i.e., CRF (21.1\%) and ARF (18.8\%) followed by cardiovascular system such as SHT (18.8\%), CHF (17.7\%), and CAD (14.4\%) followed by CVA (16.6\%). The least common system affected was respiratory system such as LRTI (3.3\%), bronchial asthma (2.2\%), and pulmonary TB (1.1\%). From this study, it was clearly indicated that most of the geriatric were affected by Kidney and cardio vascular disorder, as many of the developing countries the morbidity pattern is high for kidney and cardiovascular disorder which is quite similar to the study done in India by Kanagasanthosh et al. IJRMS Aug 2015.

Table 3: List of patients with comorbid condition $(n=66)$

\begin{tabular}{llll}
\hline S.No. & No. of diseases & No. of patients & Percentage \\
\hline 1 & 2 & 26 & 28.88 \\
2 & 3 & 34 & 37.77 \\
3 & 4 & 3 & 3.33 \\
4 & 5 & 3 & 3.33 \\
\hline
\end{tabular}

Table 4: Categorization of medications according to Beers criteria $(n=46)$

\begin{tabular}{lll}
\hline Group 1 & Group 2 & Group 3 \\
\hline Lorazepam & Modafinil & Tramadol \\
Amitriptyline & Diltiazem & Furosemide \\
Clonazepam & Theophylline & Toresamide \\
Nitrofurantoin & Metoclopramide & Aspirin \\
Zolpidem & & Carbamazepine \\
Spironolactone & & Prednisolone+NSAIDs \\
Diclofenac & & \\
Alprazolam & & \\
Prazosin & & \\
Hydroxyzine & & \\
\hline
\end{tabular}

NSAIDs: Non-steroidal anti-inflammatory drugs

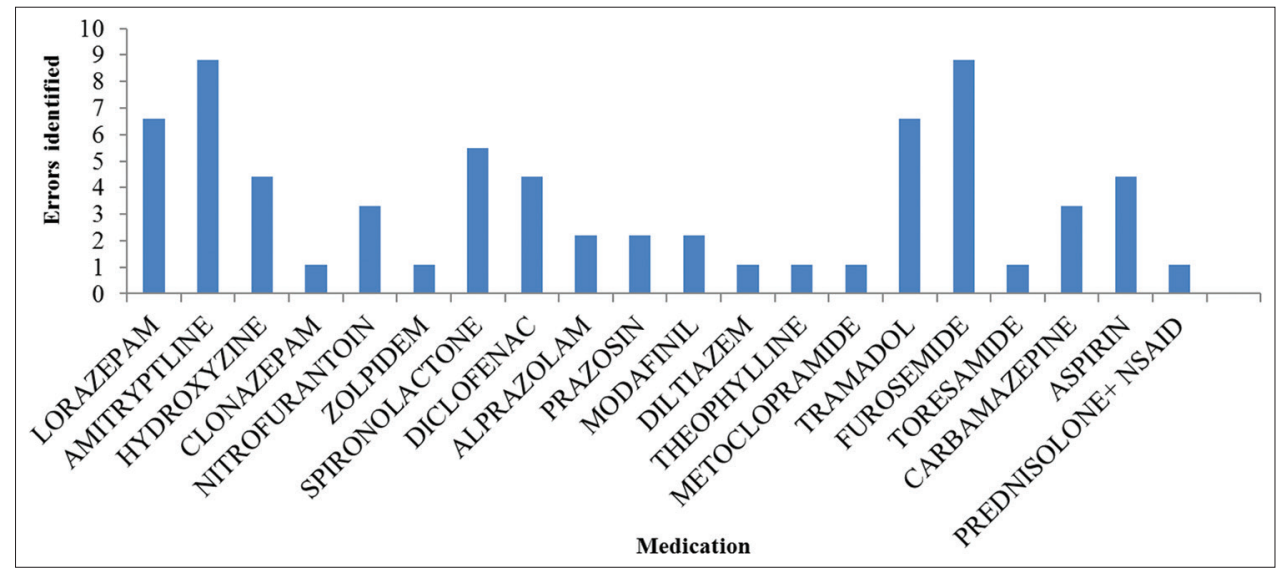

Fig. 3: Errors identified in prescriptions $(n=90)$ 
Table 5: Errors and safer alternatives in geriatrics

\begin{tabular}{|c|c|c|c|}
\hline Medication & Indication & Concern & Alternatives \\
\hline Amitriptyline & Pain & $\begin{array}{l}\text { Highly anticholinergic effects (e.g., confusion, } \\
\text { dry mouth, constipation) sedating, orthostatic } \\
\text { hypotension, cognitive impairment, delirium [8] }\end{array}$ & $\begin{array}{l}\text { Nortriptyline - } 30 \text { to } 50 \mathrm{mg} \text { per day in divided } \\
\text { dose [9] }\end{array}$ \\
\hline $\begin{array}{l}\text { Alprazolam } \\
\text { Clonazepam } \\
\text { Lorazepam } \\
\text { Zolpidem }\end{array}$ & Insomnia & $\begin{array}{l}\text { Increased sensitivity to BZDs, increased risk of } \\
\text { cognitive impairments, delirium, unsteady gait, } \\
\text { syncope, falls, accidents and fractures [8] }\end{array}$ & $\begin{array}{l}\text { Ramelteon: } 8 \mathrm{mg} \text { half an hour before sleep at } \\
\text { night }[10,11]\end{array}$ \\
\hline Spironolactone & $\begin{array}{l}\text { Congestive } \\
\text { heart failure }\end{array}$ & $\begin{array}{l}\text { In heart failure, the risk of hyperkalemia is higher in } \\
\text { older adults if taking }>25 \mathrm{mg} / \text { day [8] }\end{array}$ & Low dose. Monitor serum potassium levels [13] \\
\hline Diclofenac & Pain & GI bleeding/peptic ulcer in elderly patients [8] & Mild to moderate pain: \\
\hline Aspirin & & & $\begin{array}{l}\text { Acetaminophen - } 325 \text { to } 500 \text { mg TID max } 3000 \\
\text { mg per day } \\
\text { Celecoxib - Initially } 400 \mathrm{mg} \text {, followed by } 200 \\
\text { mg twice daily (except in heart failure)[9] } \\
\text { Moderate to severe pain: } \\
\text { Hydrocodone with acetaminophen } 5 \mathrm{mg} / 325 \\
\text { mg TID. max } 8 \text { tablets daily (gastro protective } \\
\text { therapy with PPI recommended) [11] }\end{array}$ \\
\hline Prazosin & $\begin{array}{l}\text { Systemic } \\
\text { hypertension }\end{array}$ & & $\begin{array}{l}\text { Start low dose thiazide diuretics, angiotensin } \\
\text { converting enzyme inhibitor, angiotensin } \\
\text { receptor blocker, calcium channel blocker [11] }\end{array}$ \\
\hline Diltiazem & Heart failure & $\begin{array}{l}\text { Potential to promote fluid retention and exacerbate } \\
\text { heart failure [8] }\end{array}$ & $\begin{array}{l}\text { ACE inhibitors, ARB s, appropriately titrated } \\
\text { beta blocker [11] }\end{array}$ \\
\hline Theophylline & Insomnia & CNS stimulant effects [8] & $\begin{array}{l}\text { Albuterol as needed, long acting beta } 2 \\
\text { agonist with Albuterol as needed }+/ \text { - inhaled } \\
\text { corticosteroids [11] }\end{array}$ \\
\hline Metoclopramide & Vomiting & $\begin{array}{l}\text { Extra pyramidal side effects including tardive } \\
\text { dyskinesia [8] }\end{array}$ & $\begin{array}{l}\text { Ondansetron } 4 \mathrm{mg} \text { twice daily } \\
\text { Domperidone } 10-20 \mathrm{mg} \text { daily } 3-4 \text { times } \\
\text { daily [11] }\end{array}$ \\
\hline Tramadol & $\begin{array}{l}\text { Moderate to } \\
\text { severe pain }\end{array}$ & $\begin{array}{l}\text { CNS adverse effects. Clearance is reduced when } \\
\text { creatinine clearance is reduced to }>30 \mathrm{~min} / \mathrm{ml}[8]\end{array}$ & $\begin{array}{l}\text { If it is an immediate release reduce the dose } \\
\text { Avoid extended dose [11] }\end{array}$ \\
\hline Furosemide & Edema & $\begin{array}{l}\text { May exacerbate or cause syndrome of inappropriate } \\
\text { anti diuretic hormone secretion or hyponatremia [8] }\end{array}$ & $\begin{array}{l}\text { Check sodium levels when starting or changing } \\
\text { the dose [11] }\end{array}$ \\
\hline Toresamide & Edema & $\begin{array}{l}\text { May exacerbate or cause syndrome of inappropriate } \\
\text { anti diuretic hormone secretion or hyponatremia [8] }\end{array}$ & $\begin{array}{l}\text { Check sodium levels when starting or changing } \\
\text { the dose [11] }\end{array}$ \\
\hline Carbamazepine & Seizure & $\begin{array}{l}\text { May exacerbate or cause syndrome of inappropriate } \\
\text { anti diuretic hormone secretion or hyponatremia [8] }\end{array}$ & $\begin{array}{l}\text { Check sodium levels when starting or changing } \\
\text { the dose [11] }\end{array}$ \\
\hline Prednisolone+NSAIDs & Osteoarthritis & $\begin{array}{l}\text { Increased risk of peptic ulcer disease or } \\
\text { gastrointestinal bleeding [8] }\end{array}$ & $\begin{array}{l}\text { Avoid. If not possible, provide gastrointestinal } \\
\text { protection [11] }\end{array}$ \\
\hline
\end{tabular}

BZDs: Benzodiazepine, OD: Once daily, BID: Twice daily, GI: Gastro intestinal, PPI: Proton pump inhibitor, CNS: Central nervous system, ACE inhibitor: Angiotensin converting enzyme, ARB inhibitor: Angiotensin receptor blocker, NSAIDs: Non-steroids anti-inflammatory disease

Table 6: Evaluation of medication adherence $(n=90)$

\begin{tabular}{llll}
\hline S.No. & $\begin{array}{l}\text { Categories of } \\
\text { medication adherence }\end{array}$ & $\begin{array}{l}\text { No. of } \\
\text { patients }\end{array}$ & Percentage \\
\hline 1 & High adherence & 12 & 13.33 \\
2 & Medium adherence & 32 & 35.55 \\
3 & Low adherence & 46 & 51.11 \\
\hline
\end{tabular}

The issue of polypharmacy is of particular concern in older people compared to younger individuals. Average number of medications per prescription is an important index of the scope for review and intervention in prescribing practice. It is preferable to keep the mean number of medication per prescription as minimum as possible. This will help avoid the medication-medication interactions, developmental of bacterial resistance, and will decrease hospital cost [16]. In this study, a total of 383 medications were prescribed to a total of 90 patients. $40 \%$ of the prescription had 5-9 medications followed by $38 \%$ which had 10-14 medications. The average number of medications per prescription was 7.5 which was similar to the study done by Veena et al., IORS journal of Dental and medical sciences September 2012 in India were the prevalence of polypharmacy was $88.67 \%$ and the average number of medications per prescription was 9.4. In another study conducted by Vinks et al., it was found that 
DRPs may frequently occur in adults over 65 years of age using six or more medications concomitantly.

In this study, a total of 383 medications were prescribed to a total of 90 patients for different diseases. The most common medications prescribed belonged to the category of cardiovascular medications $(14.62 \%)$ followed by CNS medications (14.09\%). This is because the second most morbidity was cardiovascular disorder, which is similar to the study done by Uma Advani et al. The Journal of Phytopharmacology 2013

In the present study, out of 90 patients $37.77 \%$ had three comorbid conditions followed by $28.88 \%$ who had two diseases. Whereas when comparing with the study by Neha Sharma et al., screening of prescriptions in geriatric population in a tertiary care teaching hospital in north India, patients were more common with more than 2 comorbid conditions.

According to American Geriatric Society Updated Beers Criteria 2015 for PIMs use in geriatric patients, our study shows almost $51.11 \%$ prescriptions had inappropriate medications. Among the three different categories in Beers criteria, in Category 1 which is medications to be

Table 7: Sex distribution in low medication adherence $(n=46)$

\begin{tabular}{lll}
\hline S.No. & Sex distribution in low adherent patients & $\mathbf{n}(\%)$ \\
\hline 1 & Male & $21(45.65)$ \\
2 & Female & $25(54.35)$ \\
\hline
\end{tabular}

avoided in geriatric patients, forms a major category of inappropriate use of medications. From this study, almost 10 different medications were prescribed to these patients from Category 1 , were Amitriptyline identified in 8 cases, followed by lorazepam identified in 6 cases, spironolactone identified in 5 cases, hydroxyzine and diclofenac identified in 4 cases, nitrofurantoin identified in 3 cases, alprazolam and prazosin identified in 2 cases, clonazepam and zolpidem are identified in 1 case. In a similar study by Fadare et al. from Nigeria, NSAIDs were the common PIMs, followed by antihistamine and amitriptyline. Category 2 - Medications which may exacerbate existing disease or syndrome. Most commonly prescribed medications were modafinil identified in 2 cases, followed by diltiazem, theophylline, and metoclopramide identified in 1 case. Category 3 - Medications to be used with caution in older adults. Most commonly prescribed medications were furosemide identified in 8 cases, followed by tramadol identified in 6 cases, aspirin identified in 4 cases, carbamazepine identified in 3 cases, toresamide, and prednisolone + NSAIDs are identified in 1 case. In a similar study by Chitra et al., IJPSR from India, Aspirin was the most common PIMs.

In this study, PIMs were frequently prescribed for CNS disorder followed by cardiovascular disorder. Another study by Eze et al. shows PIMs were prescribed for hypertension. A study by Zaveri et al., in India reported upper respiratory tract infection was most common condition for the use of PIMs in geriatric patients.

In this study, out of 90 patients, 46 patients were prescribed with inappropriate medication. Based upon benefit over risk patients were given with alternative medication. In Category 1 , amitriptyline was most commonly prescribed for pain and the safer alternative for this

Table 8: Strategies to improve medication adherence $[14,15]$

\begin{tabular}{l}
\hline Barriers \\
\hline Health-care system-related problem [14]
\end{tabular}

Provider-patient relationship

Provider communication [14]

Condition-related factors

Therapy for asymptomatic conditions [14]

Therapy-related factors

Complexity of medication regimen [15]

Lack of immediate benefit of therapy [14]

Chronic or long-term therapy [15]

Actual or perceived unpleasant side effects [14]

Social and economic factors

Low health literacy; limited English language proficiency [14]

Cost of medication [14]

Poor social support elder abuse [14]

\section{Possible strategies to overcome}

Establish a positive, supportive, trusting relationship

Assess understanding of the illness and treatment

Assess readiness to carry out the treatment plan

Identify and discuss any barriers to adherence and formulate strategies for overcoming them

Tailor medication regimens to the patient's daily routine

Reduce complexity of medication regimen and provide appropriate follow-up care Reward adherence and good or improving performance

Involve family members for social support

Avoid medical jargon

Use short words and short sentences

Give clear instructions on the exact treatment regimen, preferably in writing

Inform the patient about disease process, importance of conditions treatment or prevention, and consequences if not treated

Reduce dose frequency and use long-acting dosage forms where possible Identify combination medications that can replace two separate prescriptions Introduce reminder strategies tailored to the individual, such as pill organizers, calendars, phone reminders, etc.

Educate the patient about what to expect, including how medication works, time to onset of effect, goals of therapy, and how to monitor for effectiveness

Simplify regimen therapy

Involve family members

Cue medication taking to daily tasks or routine

Educate about what to expect from treatment and risks vs. benefits (e.g., certain side effects may be temporary)

Use pictures, diagrams or pictograms to help communicate information

Evaluate medication for cost-effectiveness; use generics; prescribe lower-cost

alternatives Prescription Assistance Programs (www.pparx.org) Enroll in Medicare

Part D prescription drug plan

Involve family member

Refer to support group

Report to adult protective services where warranted 
was nortriptyline - 30-50 mg per day in divided dose. In Category 2, modafinil was most commonly prescribed and it should be avoided in insomniac patient because it will exacerbate the symptom. In Category 3, furosemide was most commonly prescribed, use with caution and check sodium level before starting or changing the dose.

In this study, out of 90 patients, $51.11 \%$ were reported to have low adherence, followed by medium adherence (35.55\%). This is because in developing countries like India geriatrics was uneducated and poses poor knowledge about their diseases and medications. A similar study done in India showed geriatric patients were low adherent.

In this study, out of 90 patients, 46 were low adherent. Female patients showed predominance in low medication adherence than male patients which is similar to the studies done in Brazil by Antonio Augusto Schmitt Junior et al. where female patients were low adherent than male patients.

\section{CONCLUSION}

This study shows the pattern of disease prevalence in geriatric, medication use among them and the PIMs to be avoided in geriatric patients. The prevalence of polypharmacy was high and usually unavoidable in geriatric patients. The study reports shows PIM are steadily increasing. The use of inappropriate medication can be avoided using American Geriatric Society updated Beers criteria 2015. It is an important guideline which is used by physicians, pharmacists and other health care professionals and physicians follow these guidelines while prescribing medication in geriatric patients. Before dispensing the medications to the patients, it is important for the pharmacist to review the prescription for PIMs and discuss with the physicians for safer alternatives to the geriatric patients to improve the quality and efficacy of medical care given to the patients. Even though Beers criteria have been widely referred in many studies, it has not made its way into mainstream clinical practice. It is important for the prescribers to make themselves aware about the Beers criteria and it should be strictly followed for the geriatric population. Hence, this study will help physicians in clinical decision making for better pharmaceutical care in geriatric patients.

Adherence to medications is important in ensuring that therapeutic benefits are delivered to patients. However, adherence to medication has always been an issue in geriatrics patients. To improve medication adherence, it is very important for the pharmacist to make themselves updated and also to keep the patient, medication, healthcare providers, healthcare systems and factors affecting medication adherence in mind. This helps overcome the issues with suitable and individualized solutions. Pharmacists have a role in educating health-care providers and patients regarding appropriate medication dosing, adherence to medication, performing medication reviews. There is a need to ensure adherence to the medications prescribed so that the patient would be able to receive maximum therapeutic benefits.

\section{ACKNOWLEDGMENT}

The authors are extremely obliged to the cooperation of PSG college of pharmacy-PSG hospital for granting permission to carry out this project at their hospital.

\section{REFERENCES}

1. Situation Analysis of the Elderly in India. Central Statistics Officer Ministry of Statistics and Programme Implementation, Government of India, June; 2011. Available from: http://www.mospi.nic.in/mospi new/upload/elderly in india.pdf. [Last accessed on 2014 Oct 10].

2. Khanna R, Pace $\overline{P F}$, Mahabaleshwarkar R, Basak RS, Datar M, Banahan BF. Medication adherence among recipients with chronic diseases enrolled in a state Medicaid program. Popul Health Manag 2012;15(5):253-60.

3. Fick DM, Cooper JW, Wade WE, Waller JL, Maclean JR, Beers MH. Updating the Beers criteria for potentially inappropriate medication use in older adults: Results of a US consensus panel of experts. Arch Intern Med 2003;163(22):2716-24

4. Chitra B, Senthilvel N, Sowmya R, Sreerekha S, Srisha R. A study on prescribing pattern of drugs in geriatric using beers criteria at a private corporate hospital. Int J Pharm Sci Res 2015;6(11):4810-25.

5. Abeer A, Mast MR, Nijpels G, Petra JM, Dekker JM, Hugtenburg JG. Identification of drug-related problems of elderly patients discharged from hospital. Dove Med Press J 2014;8:155-65.

6. By the American society 2015 Beers Criteria Update expert panel. The American Geriatric society 2015 updated Beers criteria for potentially inappropriate medication Use in Older Adults. J Am Geriatr Soc 2015;63(11):2227-46.

7. Momin TG, Pandya RN, Rana DA, Patel VJ. Use of potentially inappropriate medications in hospitalized elderly at a teaching hospital: A comparison between Beers 2003 and 2012 criteria. Indian J Pharmacol 2013;45(6):603-7.

8. Beers M. American Geriatric Society: Beers criteria pocket Reference Card for potentially inappropriate medication for older adults; 2015. Available from www.americangeriatrics.org.

9. GHC-Safer Alternatives to Potentially Inappropriate High Risk Medications in Elderly, Medication Safety Committee, Pharmacy, Quality Division; 2015.

10. PQA. Use of High-Risk Medications in the elderly: Review and Revision of Performance Measure.PQA:2012. Available from positivehealthcare. net/california/php/for-members/drug-benefit/formulary/.

11. Safer Alternative Drugs for potentially inappropriate Drugs listed in Beers Criteria;2015. Available from HealthinAging.org.

12. Hume AL, Quilliam BJ, Goldman R, Eaton C, Lapane KL. Alternatives to potentially inappropriate medications for use in e-prescribing software: triggers and treatment algorithms. BMJ Qual Saf 2011;20(10):875-84.

13. K/DOQI Clinical Practice Guidelines on Hypertensive and Antihypertensive Agents in Chronic Kidney Disease, Guideline 12. Use of Diuretic in CKD Disease; 2002.

14. Mayland D, Richmond SJ. Improving Medication Adherence in Older Adult: What Can We Do? Available from: http//www.Vhqc.org.

15. Bebit B, Chippy LA, Shivil W, Theertha X, Selvan TT. Evaluation of impact of pharmaceutical care on improving knowledge and medication adherence in CKD patients. Int J Pharm Pharm Sci 2017;1(9):63-6.

16. Rahmawati F, Wasilah R, Pramantara DP, Azhar S, Sulaiman S. Polypharmacy and unnessceary drug therapy on geriatric hospitalized patients in Yogyakarta hospitals, Indonesia. Int J Pharm Pharm Sci 2009;1(1):6-11. 